Available online at GSC Online Press Directory

GSC Biological and Pharmaceutical Sciences

e-ISSN: 2581-3250, CODEN (USA): GBPSC2

Journal homepage: https://www.gsconlinepress.com/journals/gscbps

(RESEARCH ARTICLE)

\title{
Phytochemical screening, total hydroxycinnamic acids, total phenolic and antioxidant activity of Lavandula angustifolia Mill
}

\author{
Dumitru Mihaela Gabriela* \\ University of Craiova, Faculty of Science, Department of Chemistry, Calea București 107i, Romania.
}

Publication history: Received on 10 December 2019; revised on 16 December 2019; accepted on 24 December 2019

Article DOI: https://doi.org/10.30574/gscbps.2020.10.2.0235

\begin{abstract}
The aim of this study was the screening of phytochemicals and determination of total hydroxicinamic acids, total polyphenols and antioxidant activity of hydroalcoholic extract ofLavandula angustifolia Mill. cultivated in Craiova Romania. Phytochemical screening showed that all of samples are positively. Quantitative determination of hydroxycinnamic acids was calculated as chlorogenic acid equivalent in \% of dried plant raw material. The total polyphenol content was measured using the Folin Ciocalteu reagent colorimetric method. Antioxidant activity was determined using 2, 2-diphenyl-1-picrylhydrazyl (DPPH) free radical scavenger methods. It has established that in sample ofLavandula angustifoliathe total content of hydroxycinnamic acid derivates is $2.65 \%$, total polyphenols 1.4 mg $\mathrm{GAE} \mathrm{g}^{-1}$ DW. The hydroalcoholic extract displayed DPPH free radical scavenging activity with $85.7 \%$.
\end{abstract}

Keywords: Lavandula angustifolia Mill; Phytochemical screening; Hydroxycinnamic acids; Total phenolic; DPPH

\section{Introduction}

The use of traditional medicine is widespread and plants are indeed the first source for preparing remedies in this form of alternative medicine. Plants, especially medicinal herbs, have been used for the prevention and/or treatment of several diseases since very old times [1]. Plant extracts, such as flavonoids and phenolics, have raised public interest in their potential to act as antioxidants. In a biological system, an antioxidant can be defined as "any substance that when present at low concentrations compared to that of an oxidizable substrate would significantly delay or prevent oxidation of that substrate" [1]. Natural antioxidants are widely distributed in medicinal plants. These natural antioxidants, especially polyphenols, exhibit a wide range of biological effects, including anti-inflammatory, anti-aging, antiatherosclerosis and anticancer. The effective extraction and proper assessment of antioxidants from medicinal plants are crucial to explore the potential antioxidant sources and promote the application in pharmaceuticals.

Polyphenols of plant origin comprise a wide variety of molecules that have a polyphenol structure (i.e. several hydroxyl groups on aromatic rings), but also molecules with one phenol ring, such as phenolic acids and phenolic alcohols. Polyphenols are divided into several classes according to the number of phenol rings that they contain and to the structural elements that bind these rings to one another [2].

The main groups of polyphenols are, Fig. 1[3].

\footnotetext{
${ }^{*}$ Corresponding author

E-mail address: dummgs@yahoo.com
} 


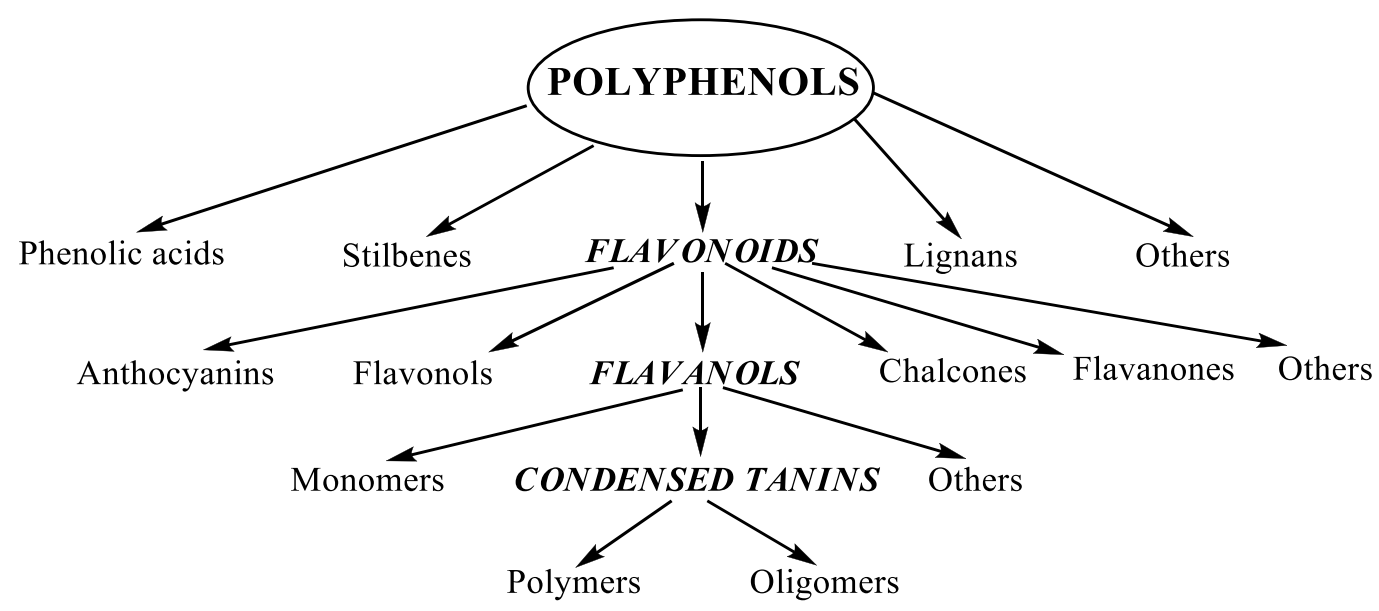

Polyphenols classification

Figure 1 Polyphenols classification

The class of compounds known as the hydroxycinnamic acidsare found both covalently attached to the plant cell wall poly-saccharides and as soluble forms in the cytoplasm. The freeform occurs very rarely in plants. Hydroxycinnamic acids and their derivates all stem from cinnamic acid, and are presentas four basic molecules: p-coumaric, caffeic, ferulic and sinapic acids, Fig. 2. The diversity of hydroxycinnamic acids and their resultant nutraceutical properties derives fromthe nature of the bonds and that of the molecule(s) involved. Inaddition, the presence of a double bond in the lateral chain of the hydroxycinnamic acids leads to the possible existence of two isomeric forms: cis (Z) and trans (E) [4].<smiles>O=C(O)/C=C/c1ccc(O)cc1</smiles>

A<smiles>COc1cc(/C=C/C(=O)O)ccc1O</smiles>

$\mathrm{C}$<smiles>O=C(O)/C=C/c1ccc(O)c(O)c1</smiles>

B<smiles>COc1cc(/C=C/C(=O)O)cc(OC)c1O</smiles>

$\mathrm{D}$

Figure 2 A- p-Cumaric acid; B - Caffeic acid; C - Ferulic acid; D - Sinapic acid

The present study was performed in order to assess the activity antioxidant potential of phenolics found in the aerial parts of Lavandula angustifolia.

Lavender belongs to the mint family Lamiaceae. While the plant is believed to have originated in Asia, it is considered native in areas ranging from the Canary Islands, to Europe, Africa, the Middle East, and parts of India. Today lavender is cultivated and grows wild in temperate zones worldwide.There are 39 species of lavender, along with numerous hybrids and cultivars. In Europe, have been used routinely as remedies: Lavandula angustifolia (English lavender), the closely related Lavandula latifolia (spike lavender), and Lavandula stoechas (French lavender). Lavender is a perennial shrub that from early June to late July produces flowers that are borne on spikes. The flowers range in color from white, to mauve, to purple.The mature bud, or flower spike of the lavender plant is the primary source of the chemicals [5].

Phenolic compounds is a large group of secondary plant metabolites. They can be utilized for preventing oxidative damage by scavenging free radicals, quenching singlet oxygen and reducing reactive species, chelating catalytic metal 
ions.This article focuses on identification of the chemical constituents and antioxidant properties of the hydroalcoholic extract of Lavandula angustifolia Mill.

\section{Material and methods}

\subsection{Plant material}

Were used freshly picked flowers of Lavandula angustifolia Mill. cultivated in Craiova (Romania) in 2017.Samples has been dried in the shade after the harvest and the dry flowers were separated from their stems.

\subsection{Preparation of alcoholic extracts for screening}

Dry flowers separated from their stems were extracted for analysis of with $100 \mathrm{~mL}$ of $80 \%$ aqueous methanol for $24 \mathrm{~h}$ in water bath at $50^{\circ} \mathrm{C}$. The obtained extracts were filtered through Whatman No. 1 filter paper and then centrifuged at $4000 \mathrm{rpm}$ for 5 minutes. The extracts were kept at $4^{\circ} \mathrm{C}$ and used for analyses.

\subsection{Phytochemical screening}

Phytochemical screening was implemented by using the standard procedures [6].

\subsubsection{Test for tannins}

Two gram of methanolic extract was placed in a test tube. Then, $5 \%$ of ferric chloride drops were added. A bluish black or greenish coloration was observed. It was an indication of the presence of pyrogallol tannins or catechol, respectively $[7,8]$.

\subsubsection{Test for flavonoids (Shinoda test)}

Two gram of methanolic extract was placed in a tube. A few fragments of magnesium were added, followed by adding $0.5 \mathrm{~mL}$ of hydrochloric acid. The reddish color was an indication of flavonoids presence [9].

\subsubsection{Test for saponins}

Approximately $1 \mathrm{~g}$ of the methanolic extract was boiled with $\mathrm{mL}$ deionized filtered and wait for $2 \mathrm{~min}$. The content was shaken vigorously. The persistent froth appearance that lasted for $15 \mathrm{~min}$ was an indication of saponins presence [10].

\subsubsection{Test for terpenoids (Salkowski test)}

Approximately $2 \mathrm{~mL}$ of chloroform was mixed with $0.5 \mathrm{~g}$ of the extract. Then, $3 \mathrm{~mL}$ of conc. $\mathrm{H}_{2} \mathrm{SO}_{4}$ was added carefully to form a layer. The red color appearance is an indication of terpenoids presence [11].

\subsubsection{Test for carbohydrates (Molisch's test)}

Two milliliter of the methanolic extract solution was mixed with $0.2 \mathrm{~mL}$ of alcoholic solution of $\alpha$-naphthol (10\%) in a test tube and followed with an addition of $2 \mathrm{~mL}$ of conc. sulphuric acid by the test tube side. At the interphase of the two layers, a bluish violet zone is formed that indicates the presence of carbohydrates or/and glycosides [12].

\subsubsection{Test for cardiac glycosides (Keller-Kiliani test)}

In a test tube $2 \mathrm{~mL}$ of glacial acetic acid containing 1-2 drops of $2 \%$ solution of $\mathrm{FeCl}_{3}$ was mixed with the methanolic extract and poured into another test tube containing $2 \mathrm{~mL}$ of concentrated $\mathrm{H}_{2} \mathrm{SO}_{4}$. Brown ring was formed. It was taken as presence of cardiac glycosides [9].

\subsubsection{Test for alkaloids}

One gram of methanolic extract was mixed with $2 \mathrm{~mL}$ of dil. $\mathrm{HCl}(1 \%)$ in a test tube. Then gently heated, followed by adding 2-3 drops of Mayer's reagent. The formation of cream or white precipitate was an indication for the presence of alkaloids $[9,10]$. 


\subsubsection{Test for coumarins}

In a test tube, $1 \mathrm{~g}$ of methanolic extract was placed and covered with filter paper moistened with dilute $\mathrm{NaOH}$, then heated on water bath for a few minutes. The filter paper was examined under UV light. Fluorescence was detected by the UV test (365 nm), yellow fluorescence regarded as positive for the presence of coumarins [13].

\subsubsection{Test for steroids (Liebermann-Burchard test)}

In a test tube, $1 \mathrm{~mL}$ of acetic acid anhydride was added to $1 \mathrm{~mL}$ of methanolic extract, the solution was cooled well in ice followed by the addition of conc. sulphuric acid carefully. Appearance of color development from violet to blue or bluishgreen was an indication for the presence of steroids [12].

\subsubsection{Test for protein (Millon's test)}

About $1 \mathrm{~g}$ of methanolic extract was mixed with $2 \mathrm{~mL}$ of Millon's reagent (mercuric nitrate in nitric acid containing traces of nitrous acid), white precipitate formed, which transformed to red upon gentle heating. It indicates presence of amino acids and protein [14].

\subsection{Determination of hydroxycinnamic acids}

Quantitative determination of hydroxycinnamic acids was calculated as chlorogenic acid equivalent in \% of dried plant raw material. Maximum absorption of chlorogenic acid reference solution occurred at $327 \mathrm{~nm}$, so the measurements were carried out at this wavelength by modified method [15].About $1 \mathrm{~g}$ (accurate weight) flowers of Lavandula angustifolia was placed in $100 \mathrm{~mL}$ flask and $70 \mathrm{~mL}$ of $20 \%$ alcohol was added. The flask was joined to condenser and heated on a water bath for 1 hour. Extraction was carried out twice. Extracts were cooled, filtered through a paper filter, quantitatively transferred to a $200 \mathrm{~mL}$ volumetric flask. The volume of filtrate in a volumetric flask was leaded to the mark by $20 \%$ alcohol and mixed. $3 \mathrm{~mL}$ of solution A were placed in $50 \mathrm{~mL}$ volumetric flask and was leaded to the mark by $20 \%$ alcohol. Absorbance of the solution was measured on Varian Cary-50spectrophotometer at a wavelength of 327 nm against 20\% ethanol blank. Content of hydroxycinnamic acid (X, \%) was calculated by a formula:

$$
X=\frac{A \cdot 200 \cdot 50 \cdot 100}{E_{1 \%, 1 \mathrm{~cm}} \cdot \mathrm{m} \cdot 3 \cdot(100-W)}
$$

where, A - absorption of the studied solution; $\mathrm{E}_{1} \%, 1 \mathrm{~cm}$ - specific absorption rate of chlorogenic acid, which is equal to $531 ; \mathrm{m}$ - weight of the plant material, g; $\mathrm{W}$ - the loss in weight at drying, \%.

\subsection{Determination of total polyphenol (TP)}

The total polyphenol content was measured using the Folin Ciocalteu reagent colorimetric method. To $800 \mu \mathrm{L}$ of deionised water, $50 \mu \mathrm{L}$ of Folin-Ciocalteu reagent and a volume of sample ranging from 10 to $50 \mu \mathrm{L}$ were added and accurately mixed. After $1 \mathrm{~min}, 100 \mathrm{~mL}$ of $20 \%$ sodium carbonate solution was added and mixed. Deionised water was then added up to a volume of $1 \mathrm{~mL}$. The solution was carefully mixed and total phenol content was spectrophotometrically estimated at $765 \mathrm{~nm}$ after $2 \mathrm{~h}$ incubation. The results were expressed as mg Gallic acid equivalents (GAE) g-1 of Lavandula angustifolia extracts using a standard curve, Fig. 3, generated with $10 \mu \mathrm{g}, 20 \mu \mathrm{g}$, 40 $\mu \mathrm{g} 60 \mu \mathrm{g}, 80 \mu \mathrm{g}$ and $100 \mu \mathrm{g}$ Gallic acid per $\mathrm{mL}[16,17]$. 


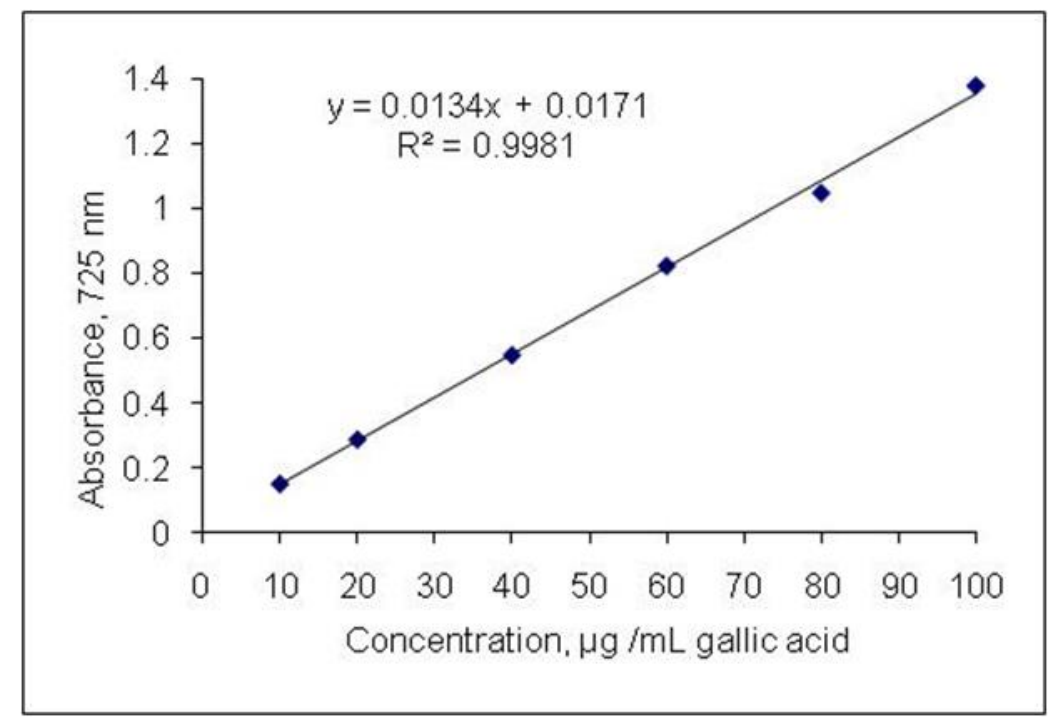

Figure 3 Standard curve of gallic acid

\subsection{DPPH radical scavenging activity}

The DPPH radical scavenging activity (SA) was determined spectrophotometrically using the DPPH method. Briefly, 1 $\mathrm{mL}$ of extract solution in distilled water or $1 \mathrm{~mL}$ of distilled water (blank) was mixed with $2 \mathrm{~mL}$ of DPPH solution $(2 \mathrm{mg}$ of DPPH was dissolved in $50 \mathrm{~mL}$ of methanol). The range of the investigated extract concentrations was $0.002-0.5 \mathrm{mg}$ $\mathrm{mL}^{-1}$. The mixture was shaken vigorously and left at room temperature for $30 \mathrm{~min}$, then the absorbance was read at 517 $\mathrm{nm}$ using a spectrophotometer Varian Cary-50. The capability to scavenge the DPPH radicals (DPPH radical scavenging activity) was calculated using the following equation:

SA $(\%)=100 \times\left(\right.$ Ablank $\left.-A_{\text {sample }}\right) / A_{b l a n k}$

where: Ablank is the absorbance of the blank and Asample is the absorbance of the sample.

[17].

\section{Results and discussion}

Phytochemicals are the core of phytomedicines; their therapeutic efficiency directly correlates with the presence of various phytochemicals. Table 1 shows the phytochemical screening of hydroalcoholic extract. Preliminary phytochemical screening experiments are commonly performed to promote a guidance of substantial phytochemicals that may be involved in the antioxidant activity of plant extracts [18].

Table 1 Phytochemical screening of hydroalcoholic extract of Lavandula angustifolia

\begin{tabular}{llll}
\hline Phytoconstituents & Extract & Phytoconstituents & Extract \\
\hline Tannins & + & Cardiac glucosides & + \\
Flavonoids & + & Alkaloids & + \\
Saponins & + & Coumarines & + \\
Terpenoids & + & Steriods & + \\
Carbohydrates & + & Proteins & + \\
\hline
\end{tabular}

As the result of the carried out investigations, the spectrophotometric method for determination of the totality of hydroxycinnamic acid derivates, expressed as chlorogenic acid. It has established that in sample of Lavandula 
angustifolia the total content of hydroxycinnamic acid derivates is $2.65 \%$. The results obtained in this study showed a significant level of phenolic compounds in the ethanolic extract of flowering aerial parts.

The phenolic content was expressed as Gallic acid equivalent and was deduced from the pre-established calibration curve (Fig.1) and calculated using the following equation:

$\mathrm{Y}=0.0134 \mathrm{x}+0.0171 ; \quad \mathrm{R}^{2}=0.9981$

where, $\mathrm{Y}=$ absorbance, $\mathrm{x}=$ corresponding concentration $\left(\mu \mathrm{g} \cdot \mathrm{mL}^{-1}\right)$ and $\mathrm{R}^{2}=$ correlation coefficient.

The amount of total polyphenols found in the ethanolic extract of Lavandula angustifoliais of $1.4 \mathrm{mg}^{\mathrm{GAEg}}{ }^{-1} \mathrm{DW}$. Polyphenols are strong antioxidants that complement and add to the functions of antioxidant vitamins and enzymes as a defense against oxidative stress caused by excess reactive oxygen species (ROS) [19]. Phenolic antioxidants were proved to interact with free radicals according to the four mechanisms [20,21]:

- direct hydrogen atom transfer [HAT]

$\mathrm{ArOH}+\mathrm{X}^{\bullet} \rightarrow \mathrm{ArO} \bullet+\mathrm{XH}$

- electron transfer-proton transfer [ET-PT]

$\mathrm{ArOH}+\mathrm{X}^{\bullet} \rightarrow \mathrm{ArOH}^{\circ}+\mathrm{X}^{-} \rightarrow \mathrm{ArO}^{\circ}+\mathrm{XH}$

- proton-coupled electron transfer [PCET]

$\mathrm{ArOH}+\mathrm{X}^{\bullet} \rightarrow\left[\mathrm{ArOH}^{*} \ldots \mathrm{X}^{\bullet}\right] \rightarrow\left[\mathrm{ArO}^{\circ}+\ldots \mathrm{X}^{\bullet}\right] \rightarrow \mathrm{ArO}^{\circ}+\mathrm{XH}$

- sequential proton loss electron transfer [SPLET]

$\mathrm{ArOH} \rightarrow{ }^{\mathrm{H}+} \mathrm{Ar}^{-} \rightarrow \mathrm{H}^{-} \mathrm{ArO}+\mathrm{X}^{-} \rightarrow^{\mathrm{H}^{+}}+\mathrm{ArO}^{-}+\mathrm{XH}$

Hydroxycinnamic acids are important phytochemicals possessing significant antioxidants properties. Several investigators have studied in vitro antioxidant activity of hydroxycinnamic acids in detail. Most of the reports indicated that the presence of an unsaturated bond on the side chain of hydroxycinnamic acids is vital to their activity. The structural features that were reported to be of importance to the antioxidant activity were categorized as follows: modifications of the aromatic ring, which include alterations in the number and position of hydroxy groups and insertion of electron donating or withdrawing moieties as well as modifications of the carboxylic function that include esterification and amidation process. Most of the investigations concluded that the presence of ortho-dihydroxy phenyl group (catechol moiety) is of significant importance to the antioxidant activity, while, the presence of three hydroxy groups does not necessarily improve the activity [22].

The total phenolic compounds and hydroxycinnamic acids, may play important role in determined antioxidant activity of extract obtained from Lavandula angustifolia.

The antioxidant activity of the Lavandula angustifolia extract was measured on the basis of the scavenging activity of the stable 1,1-diphenyl 2-picrylhydrazyl (DPPH) free radical. DPPH scavenging activity of Lavandula angustifolia was evaluated $85.7 \%$.

The results are supported by findings from literature [23 - 26].

\section{Conclusion}

The phytochemical screening of hydroalcoholic extract of Lavandula angustifolia shown the presence of pharmacologically active substances such as tannins, flavonoids, saponins, terpenoids, carbohydrates, cardiac glucosides, alkaloids, coumarines, steroids and proteins. Positive high correlation between phenolic acids contents and the ability to reduce DPPH indicate that the phenolic compounds are main co-authors of the antioxidant activity of Lavandula angustifolia. Based on the results obtained in the present study, it is concluded that the hydroalcoholic extract 
of Lavandula angustifolia possess substantial amounts of phenolic compounds. Thus, hydroalcoholic extract can be considered a good source of natural antioxidants and might be used alone or as an adjunct to other drugs in medicine.

\section{Compliance with ethical standards}

\section{Acknowledgments}

The author are grateful to everyone who contributed in achieving this feat.

\section{Disclosure of conflict of interest}

There is no conflict of interest with publishing the present data of the study.

\section{References}

[1] Halliwell B, Murcia MA, Chirico S and Aruoma OI. (1995). Free radicals and antioxidants in food and in vivo: what they do and how they work. Food Science and Nutrition, 35, 7-20.

[2] D'archivio M, Filesi C, Di Benedetto R, Gargiulo R, Giovannini C and Masella R. (2007). Polyphenols, dietary sources and bioavailability. Annali dell'Instituto Superiore di Sanita, 43(4), 348-361.

[3] Setti L, Faulds C and Giuliani S. (2001). Hydroxycinnamic acids as natural antioxidants. La Chimica e l'Industria, $83,1-5$.

[4] Marat JP.Lavender (Lavandula angustifolia)-Botany, Therapeutic Uses, Constituents, Pharmaco, Adverse Effects.

[5] Khayyat S, Al-Kattan M and Basudan N. (2018). Phytochemical Screening and Antidermatophytic Activity ofLavender Essential Oil from Saudi Arabia. International Journal of Pharmacology, 14(6), 802-810.

[6] Ciulci I. (1994). Methodology for the analysis of vegetables and drugs. Chemical Industries Branch, Division of Industrial Operations, UNIDO, Romania, 24-67.

[7] Asgharian P, Afshar FH, Asnaashari S, Lotfipour F, Baradaran B, Zolali E, Nikkhah E andDelazar A. (2017). Evaluation of various biological activities of the aerial parts of Scrophularia frigida growing in Iran. Iranian Journal of Pharmaceutical Research, 16, 277-289.

[8] Yadav RNS and Agarwala M. (2010). Phytochemical analysis of some medicinal plants.Journal of Phytological, 3 , 10-14.

[9] Ranjit PM, Santhipriya T, Nagasri S, Chowdary Y, Pasumarthy N and Gopal V. (2012). Preliminary phytochemical screening and antibacterial activities of ethanolic extract of Calotropis procera flowers against human pathogenic strains. Asian Journal of Pharmaceutical and Clinical Research, 5, 127-131.

[10] Khan FA, hussain I, Farooq S, Ahmad M, Arif M and Rehman IU. (2011). Phytochemical creening of some Pakistanian medicinal plants.Middle-East Journal of Scientific Research, 8, 575-578.

[11] Usman H, Abdulrahman FI and Usman A. (2009). Qualitative phytochemical screening and in vitro antimicrobial effects of methanol stem bark extract of Ficus thonningii(Moraceae). African Journal of Traditional, Complementary and Alternative Medicines, 289-295.

[12] Pochapski MT, Fosquiera EC, Esmerino LA, Dos Santos EB, Farago PV, Santos FA and Groppo FC. (2011). Phytochemical screening, antioxidant and antimicrobial activities of the crude leaves extract from Ipomoea batatas (L.) lam. Pharmacognosy Magazine, 7, 165-170.

[13] Debela A. (2002). Manual for Phytochemical Screening of Medicinal Plants. Ethiopian Health and Nutrition Research Institute, Addis Ababa, Ethiopia, 35-42.

[14] Lenchyk LV. (2016). Determination of Content of Flavonoids, Hydroxycinnamic acids and Volatile compounds in Plum leaves. International Journal of advances in Pharmacy, Biology and Chemistry, 5(2), 131-136.

[15] Dumitru MG. (2016). Increasing the Oxidative Stability of Oil Extracted from Jatropha curcas L. Seeds by Adding Oil Extracted from Roasted Vitis vinifera Seeds. Revista de Chimie (Bucharest), 67(6), 1127-1130.

[16] Dumitru MG and Ganescu A. (2017). Obtaining Natural Biopolymers Films of Quercus robur L and Roasted Seeds of Vitis vinifera Grapes. Materiale plastice, 54(2), 316-320. 
[17] Sirohi R and Sagar R. (2018). Phytochemical screening, total phenolic and total flavonoid content and antioxidant activity of Lavandula stoechas Linn. Asian Journal of Pharmaceutical Education and Research, 7(2), 115-123.

[18] Tsao R. (2010). Chemistry and Biochemistry of Dietary Polyphenols.Nutrients, 2(12), 1231-1246.

[19] ShangYJ, Liu BY and Zhao MM. (2015). Details of the Antioxidant Mechanism of Hydroxycinnamic Acids. Czech Journal of Food Sciences, 33(3), 210-216.

[20] Urbaniak MA and Bluyssen HAR. (2015). A theoretical antioxidant pharmacophore for natural hydroxycinnamic acids. Open Chemistry, 13, 17-31.

[21] Razzaghi-Asl N, Garrido J, Khazraei HBorges F andFiruzi O.(2013).Antioxidant properties of hydroxycinnamic acids: a review of structure-activity relationships, Current Medicinal Chemistry, 20(36), 4436-4450.

[22] Adaszynska-Skwirzynska M andDzieciol M.(2017).Comparison of phenolic acids and flavonoids contents in various cultivars and parts of common lavender (Lavandula angustifolia) derived from Poland.Natural Product Research, 31(21), 2575-2580.

[23] Bival SM, Jadranka VR, Biljana B, Kindl M and Vladimir-Knezevic S. (2014). Total Hydroxycinnamic Acids Assay: Prevalidation and Application on Lamiaceae Species.Food Analytical Method, Published online.

[24] Nurzynska-Wierdak R and Zawislak Z. (2016). Chemical composition and antioxidant activity of lavender (Lavandula angustifoliaMill.) aboveground parts. Acta Scientiarum Polonorum Hortorum Cultus, 15(5), 225-241.

[25] Andrys D, Kulpa D, Grzeszczuk M, Bihun M and Dobrowolska A. (2017). Antioxidant and antimicrobial activities of Lavandula angustifolia Mill. field-grown and propagated in vitro, Folia Horticulturae, 29(2), 159-178.

\section{How to cite this article}

Dumitru MG. (2019). Phytochemical screening, total hydroxycinnamic acids, total phenolic and antioxidant activity of Lavandula angustifolia Mill. GSC Biological and Pharmaceutical Sciences, 10(2), 001-008. 